\title{
Global warming, policy suggestion to logistics industry about 'Energy saving and emission reduction'
}

\author{
Linbo Jing*and Xuefeng Wang**
}

\begin{abstract}
This paper summarizes the severity of global warming, collaboration and endeavor within international government and the trend of international development for "energy-saving and emission reduction." The Chinese government is enduring high pressure under the environment of "global warming" and "energy-saving and emission reduction" and it has made a policy for "energy-saving and emission reduction." Based on this, we analyzed the possibility and feasibility for our logistics to "energy-saving and emission reduction," then propose some solutions for our logistics industry to development and "energy-saving and emission reduction."
\end{abstract}

Keywords: global warming, modern logistics industry, energy saving and emission reduction.

\section{Introduction}

A big snow calamity which swept many provinces of South China turned the "South Nation" that has been always warming into an "ice and snow world" at the end of 2007. It made us seem to hear the footsteps of "the day after tomorrow." Rainstorms are gradually replacing snowstorms in the South Pole, the glaciers of the North Pole are crying, many lakes are vanishing, and coral reefs are fading away. The prime criminal behind these events is "Global Warming."

Submission Date: 05/20/2009 Revision Date: 11/02/2009

Acceptance Date: 11/02/2009

* Corresponding Author, Assistant Director, Institute of Finance and Trade, Chinese Academy of Social Sciences, 2 Yuetan Beixiaojie St., Beijing 100836 China. Tel:+86 10 68047510, E-mail: jinglingbo@sina.com

** Ph.D. Candidate, Chinese Academy of Social Sciences, 2 Yuetan Beixiaojie St., Beijing 100836 China.. E-mail: mayandcalf@126.com 


\section{The severity of global warming}

Weather change has been a hot topic for academe and an important issue for every government from 90 years 20 century. Hitherto, the Intergovernmental Panel on Climate Change (IPCC) has issued 4 reports in 1990, 1995, 2001 and 2007. These reports are mostly important groundwork for international groups to understand the issue of the weather change. The experts figure that the fourth report of IPCC-that the loss of the world GDP by global warming will be small if we take availability reduction measure as soon as possible and can control the greenhouse gas (GHG) concentration peak value at 445ppm-710ppm, while the GHG will continue increasing and it will bring severity crisis to economic and society if we can't improve our policy or our reduction measure.

Through four reports of IPCC, we can confirm some conclusions. First, the weather warming can be affirmed and the biggest reason is related to human activity; second, some people may endure menace by weather warming; third, we should adopt some measure immediately to control the GHG at a stable level.

\section{Intergovemmental cooperation for energy-saving and emission reduction}

Meteorologists raised the issue of weather warming in the 70s, along with awfully high temperature weather continual appear, the understanding to the relation of weather change with human activity and the relation of the survival environment with weather change is gradually deepen for human; there is unanimous for International society that we should positively reaction to the weather warming.

The question of weather changing is one of the important issues which challenge for human in most scale, range and deep. Few decades, Intergovernmental Panel have made active, hard explore for reacting to the weather changing collaboratively. The weather cooperate control at intergovernmental level through three phases. At the first phase, they established the ultimately object and some basic principle in law, from "The frame pact of United Nations climate change" negotiation starting in 1990, to subscribe the "pact" in 1992 and to the "pact" effect in 1994. During the second phase, it began an important milestone to control "Global Warming" from discussing "the first protocol constituted" to achieve "Kyoto Protocol" in Kyoto conference in 1997, to the protocol formal goes into effect in 2005. At the third phase, they will seek the extend scheme of "Kyoto protocol" together by every part and contrive the target to reduce GHG and make project to act for 2050, the phrase means the end of "Kyoto protocol" by starting "the weather negotiate" in 2005, to the "Bali Road Map" achieved in 2007.

"The Convention of world Climate Change" will convene in Copenhagen in 2009. There are many suspense when the course is be end and what is its finally fruits; but we can 
affirm that every leaguer nation has begun to actively seek and strengthen for the scheme to mitigate global warming in the collaborate frame of the "U.N Pact of Weather Change" and "Kyoto Protocol."

\section{The policy and target of china for 'Energy-saving and emission reduction'}

\subsection{The pressure to China government for 'Energy saving and emission reduction'}

Chinese population is top one; economic gross is top three and its energy consumed is top one too. Quantity emission of carbon dioxide $\left(\mathrm{CO}_{2}\right)$ has exceeded America's and become the top one in the world. The quantity emission of $\mathrm{CO}_{2}$ by China will be 8,600 million tons, far exceeding 6,400 million tons by America. So China government faces to awful pressure from international under the condition of "Global Warming" and "energy saving and emission reduction."

\subsection{China government policy and its effect for 'Energy saving and emission reduction'}

"The law for energy saving and emission reduction of China" began to implement in January 1998, which indicated that the energy saving work began to gradually bring to legal and standard system. "The scheme program of energy development in medium and long term" passed in June 2004, which showed that the energy program began to be brought into the collectivity program of economic and social development. Premier Wen Jiabao suggest, in the "Report of Government" in 2007, that we should decrease the energy consumed, reduce the pollution letting and down the cost of our environment. State Department has constituted "the leader group" for the work of "energy-saving and emission reduction," the leader is Wen Jiabao. The measure enhanced the power and effect of the work. State Department published "the colligate scheme for energy saving and e emission reduction," cleared the target for reducing work in the stage of "the eleventh five year program."

The energy consumed increased fast along with economic rapid development, while the energy consumed per GDP shows downtrend. The energy consumed per GDP was 1.49 ton standard coal, down to 1.22 ton in 2005, and to 1.03 ton in 2007. The efficiency of energy using is improved and the effect of reduction policy begins to appear.

\subsection{China government target to 'Energy saving and emission reduction'}

China's government has implemented the most active policy for energy saving and 
emission reduction. It suggests that the energy consumed should decrease $20 \%$ and pollution letting should reduce 10\% compare to the end of "Tenth Five Year Program" in period of "The Eleventh Five Year Program," which means the energy consumed should decrease from 1.22 tons to 0.97 tons standard coal. In order to achieve the target of "The Eleventh Five Year Program" made by the Chinese government and alleviate the stress come from home and outland, to achieve the task of sustainable development, it demand not only the government to adjust its existing energy consumed model but also every industry in the social economic system all should adjust its model and try hard to decrease energy consumed and emission reducing.

\section{China logistics development and energy consumed}

\subsection{Logistics status established in nation level}

Logistics gradually shape and rapid develop along with the economic continue, rapid development. There are three parts in our logistics which composed with state, foreign capital and civil operation. The logistics has gained recognition and support by government in the developing process. The Economic and Trade Department etc. together promulgated "About some opinion to rapid modern logistics development" in March 2001; "Association of Material And Circulation" changed to "China Federation of Logistic and Purchasing" in April 2001; "National Development and Reform Commission" and other 9 departments together published "About the Opinion to Promote Modern Logistic Development in Our Country" in August 2004. It was advised that modern logistic should actively develop in "Eleventh Five Year" developing scheme, so the logistics enter into a new stage with rapid, continue and stable development.

\subsection{Development status of China logistics industry}

China logistics has improved much in scale, capability and level of service, its traits as follows:

(1) The logistics scale status

The general scale of logistics can't be reflected exactly because China has not established its logistics industry statistical system. In order to approximately reflect logistics industry scale, the paper use freight age quantity and transport kilometer to substitute the scale of logistic, based on the trait that logistics can’t finished without transportation. China 
has achieved 227,580 million ton and 101,418,810 million ton kilometer by all transportation in 2007. We can confer from these data that the scale of logistics should be hugeness in China.

(2) Infrastructure and service capability status

The railway using was 77.1 thousand kilometer, the lorry was 558,483 and its carry capability was 34,221 thousand ton in 2006. The road using was 3,457 thousand kilometer, the civil auto was 8,025.8 thousand and carry cargo was 6,406.6 thousand which capability was 28,226.9 thousand ton. Freshwater open 123.5 thousand kilometer and its main berth was 7,044 which length was 389,353 meter; civil powerboat was 157,805 which carry capability was 98,241,489 ton; barge was 36,555 which net carry capability was 12,015,595 ton. The main port berth was 3,804 which length was 417,749 meter in inshore and its throughput capability of was 3,421,910 thousand tons.

The service capability of China's logistics industry starves for upgrade. The infrastructure and equipment of existing logistics can't exert its efficiency because traffic, material circulate and information service can't comply with the law to organize and manage the logistic operations; simultaneity, the logistics socialization is low and the scale of logistics enterprise is small. The existing policy restrict the service level upgrade especially manage and execute policy system.

\section{(3) The status of service level}

Service levels focus on quality. Logistics service levels have 3 indices that are logistics time, expenses and efficiency which are all not enough ideal. Logistics time is much too long which is $90 \%$ in whole supply time. Logistics expense is higher which account for $18.4 \%$ in GDP in early half year 2008. The logistics efficiency is too low that the added value of logistics just is $5.67 \%$ in GDP 2007, while the index is about $10 \%$ in America; the transportation quantity per 10 thousand Yuan is 3,942 ton-kilometer while the data is 870 in America, which means China logistic industry has large gap to America standard in development level.

\subsection{Development level and energy consumed}

The traffic efficiency is gradually improving and the freight arrange trend to be reasonable. Transport quantity is continually downing per GDP, which from 14.42 ton to 8.84 ton per ten thousand Yuan. Freight turnover decreases from 4,524 ton-kilometer in 1999 to 3,942 ton-kilometer in 2007 per ten thousand Yuan. But there is a huge gap comparing to the developed country which no less than 1,000 ton-kilometer per ten thousand 
Yuan.

Logistics turnover efficiency shows some increasing, while its contribution to GDP compare to its energy consumed shows down trend. The good turnover consume energy quantity down from 0.228 ton-kilometer in 1999 to 0.204 ton-kilometer per ten thousand Yuan, while the energy consumed rise from 7.15 kilogram standard coal to 9.07 kilogram standard coal per ten thousand Yuan.

In a conclusion, China logistics industry is developing rapid while its level is still laggard and its service capability is still lower. So in order to suit to the trending and traits of modern logistics industry, China should catch the history chance for logistics industry to develop and support our modern logistics industry. At the same time, China should try hard to reduce energy consumed and its emission because the logistics industry has the trait that is high energy consumed.

\section{Logistics contribution to GHG emission and China logistics energy consumed}

\subsection{Logistics contribute to the emission of GHG}

According to the report by IPCC, $\mathrm{CO}_{2}$, which accounts for $76 \%$ in all GHG while burned fossil fuels produced are $56.6 \%$, is premier criminal to global warming. Transportation contribute $\mathrm{CO}_{2}$ to GHG is $13.1 \%$, top 5 in all industry. The Transportation has incumbency duty to energy-saving and emission reduction for its higher contribution to GHG

\subsection{Energy consumed by China logistics}

The logistics industry consumes energy mainly in its transportation and storage phases. So we use the energy consumed by transportation and storage to substitute the energy consumed by logistics industry. Then, the energy consumed shows large increased, which increased from 94,240 thousand ton to 20,643 ton standard coal, and its increased degree larger exceed the gross energy consumed increased degree. The energy consumed of logistics to GDP ratio shows downtrend, which from 10.31 in 1999 to $8 \%$ in 2007, while its to gross energy consumed shows uptrend, which from $6.9 \%$ in 1999 to $7.77 \%$ in 2007 . It indicates that the work is lag for logistics industry to energy-saving and emission reduction in the condition that the nation policy calls for to energy-saving and emission reduction.

Logistics mainly use gasoline and diesel oil as energy source. Gasoline and diesel oil 
was consumed by logistics have been increasing which rate to all energy was $37.43 \%$ and $35.65 \%$ in 1999 , enhanced to $50 \%$ and $54.3 \%$ individually. According it to speculate, China logistics industry contribute to GHG should be about $10 \%$. We conclude that the industry has much potential to energy-saving and emission reduction. So, we should highly pay more attention to it.

\section{The potential and feasibility for China to save energy and reduce emission}

Logistics will be in a more rapid development phase while the government pays more attentions to modern logistics, itself need for developing and boosted by information technology. The traits of logistics decided that the demand for more energy will be into a new stage. The logistic energy consumed is 2.33 times in 2007 relative to 1999 . We concluded that the energy consumed will keep on increasing rapidly along with the scale of the logistics continually scale-up.

The logistics has large potential to save energy and reduce emission because its status, traits and development trend. It should arouse the attention by government officer, logistic industry leader and scholar. They should try hard to do well the task of energy-saving and emission reduction with policy, law and code, industry restriction and manage, technology, operation etc many action. They should together contribute to the government task and global warming mitigation.

\subsection{China logistics develop traits}

\section{(1) Starting later and development rapid}

The corporations that belong to the manufacturing industry or to the circulation industry all gradually understand the importance of logistics at later 90's 20 century. The logistics began to rapid development with international, transfer and new logistics enterprise together impelling. The total amounts of logistics were 75.23 trillion Yuan, comparatively increase 26.2\%; total expenses were 4.54 trillion Yuan, comparatively increase 18.2\%; added values were 1.698 trillion Yuan, comparatively increase 20.3\%, which was $17.6 \%$ of the gross added values of social service industry and 6.9\% of GDP in 2007. The logistics contribution to service industry and national economic was more aggrandize. Through approximately calculating, the total amounts of logistics are 88.82 trillion Yuan, comparatively increase 18.1\%; total expenses are 5.21 trillion Yuan, comparatively increase $14.7 \%$, added values are 1.94 trillion Yuan, comparatively increase 14.6\%. Logistic industry is entering higher way to develop. 
(2) Large potential to development

The large scale economic need support by larger logistics. The GDP was 25.73 trillion Yuan of China in 2007; though China will be affected by the financial crisis which broke out in 2007, intensified in 2008, which will lead the development speed of china to lower, but the rapid develop trend will not be changed in long run time. This indicate that Chinese economic will have much huger demand for logistics based on the economic base condition of China. Secondly, Chinese logistics are still in the initial phase. The function of logistics supplier is singleness, which means the added value service is weak. In fact, the base service income is $85 \%$ and other income from added value only is $15 \%$ for supplier. There still has a larger gap to really modern logistic standard.

(3) Decentralization in management, existing obstacle in mechanism and system

The infrastructure, logistic technology and equipment, industry policy, tax and traffic standard etc, relating to logistic development, each belongs to different government authority. At the same time, many authorities in China lack enough knowledge of modern logistics and also lack collaborative and harmonious strategies. So, the management from government to logistics enterprise is a intricacy system. Otherwise the local protection is rather patency. Some local Government setup some obstacle in traffic, tax and business administration to restrict the enterprise's running which not belongs to the district. The management situation restricts the reasonable plan and program as a whole of enterprise, obstruct the social process of logistic and also restrict e-commerce to spread and apply. Even more, the condition will impact the whole function and the benefits of the logistics.

(4) Small in logistics enterprise scale, low in specialization level

The logistic enterprise scale is small, complex company is few. The modern level of transport, storage is still low. The center of logistics and distribution's construction and container transport develop slowly. The phenomena for enterprise with every function is very rife, which made inefficacy process increase and lead the speed low and the cost rise, result in waste on logistics process. The logistics enterprises have not achieved electron, still not achieve integration on production, supply and sale, which affect the efficiency of logistics.

(5) Without right law environment

The policy to develop the logistics industry is still not constituted or published while the exiting codes related to logistics with section and territorial, sometimes with protection 
tint. The enterprises of logistics have no effect code system because there are no uniform law codes. EC-logistics has no one intact technology standard which can't suit the demand of logistic developing.

There is no united code or rule to comply with competition, so the enterprise also has no united rule to abide by when it want enter into or back out from the market. Due to without positive cognition and division, the catalog book has not logistic corporation in business administration department. Setting up logistics corporation still be restricted by varieties limited and with numerous and trivial procedure. Professional organization and corporation with function to hatch has no status in law. These all restrict modern logistics industry more deep development.

\subsection{Feasibility for China to save energy and reduce emission}

\section{(1) Policy feasibility}

The energy consumed per GDP shows stepwise downtrend while the logistics used energy shows uptrend to gross energy consumed in the condition that home and outside all be asked to save energy and reduce emission. The energy used per GDP was from 1.49 ton standard coal in 1999 to 1.22 ton and then to 1.03 ton standard coal; the logistics used energy to gross energy consumed was $6.9 \%$ in $1999,7.42 \%$ in 2005 , and $7.77 \%$ in 2007 . It suggest that the policy for "energy-saving and emission reduction" have had some effect and the logistics "energy saving" work was laggard compared to the whole "energy-saving and emission" reduction work scheme. As high energy consumed industry, the government should pay more attention to logistics to improve the reduced effect.

\section{(2) The basic feasibility}

The freight capability and scale of logistics has increased much. To the end of 2007, there are 3,587 thousand kilometers of road, 78 thousand kilometers of railway, 123.5 thousand kilometers of freshwater. The quantity of freightage was 3,587 thousand tons, cargo turnover was 101,418.81 hundred million tons/kilometer; civilian has 43,580 thousand motorcars. The freight corporation size is scale-up, large-scale, high science and technology and modernization. The ideas to logistics operation gradually upgrade. This is good scale-base for the task for energy-saving and emission reduction work.

\section{(3) The technology feasibility}

The frame of logistics technology system has been continually optimizing and information technology applied rapid improving. Technology equipment has ameliorated 
notability. It has just shaped the subdivision special transportation market and gradually evolving to large and specialization. At the same time, logistics information is improving accelerated: the intellective card of container conveyance and electron file of danger material were used one after the other, so the service level has been improved.

(4) Industry management and execution feasibility

The logistics industry has set up "Logistics Association of China" (LAC) and "China Federation of Logistics and Purchasing (CFLP)." LAC has begun to perform its industry management and harmonious work; CFLP has begun to statistic the logistics running data. It is a good beginning though the function is not perfect for it is not including energy using. LAC or CFLP can take on the responsibility of industry manage role that including management, implement, supervision and statistic. It should be had some maneuverability if we can subdivide the mission at industry management and organization level.

\section{(5) Trend feasibility}

Now is the time for the logistics industry to upgrade its industry structure. The general current is energy-saving and emission reduction in home and overseas. The current provides some advantage surroundings and industry safeguard for logistics industry to adjust and its task for energy saving and emission reduction. Additional, the infrastructure's effective amelioration also offers foundation safeguard for logistics to enhance efficiency and energy saving and emission reduction.

\section{Logistics industry countermeasure and policy suggestion for}

\section{'Energy-saving and emission reduction'}

As "a new increasing economic point" and "the third fountain of profit," logistics industry has become an important industry in national economics; while as a high energy using and GHG emission industry, logistics has had biggish influence industry to "Global Warming." So, the Governments should constitute the strategy program of logistics when they make policy to impel the industry development; the government should do well the task to "energy-saving and emission reduction," to reduce GHG emission and to mitigate weather changing. So our suggestion as follows: 


\subsection{Constitute special organization for logistics industry in national government organization}

Now, many developed countries construct their new world economic structures depending on "Economic Globalization," "Information High Speeding" and "International Logistics Netting" strategies. We should construct our logistics industry development strategy as an important part to develop strategy of our national industry because logistics industry has been affirmed its status in our national industries. In fact, we already have the capability to develop our modern logistics relying on our infrastructure and equipment. It is the question that we have no special government organization to conform the new logistics from the existing logistics resource. Though we have set up LAC and CFLP, they are only association and can't delegate government's functions and duty. The result is their decision-making without authority and force effect. So, the government should construct special department to charge for logistics plan as a whole, programming, management, boosting and supervising the logistics development and "energy-saving and emission reduction," charge for its strategy at national development level.

\subsection{Constitute common logistics law, code and criterion for "Energy saving and emission reduction"}

The modern logistics industry is a complex industry which crosses many departments, territories and industries. The functions relating to it belong to different departments, which made our code and law decentralization and have no uniform, harmonious law system. The condition leads the code to have no strong effect and have no powerful restriction to the main corporation's action of logistics industry and disarrange the order of logistics. It has affected the development, operation effect and "energy-saving and emission reduction" work, because the cooperation and communication are not enough for the relating department. We are starving for constituting the common code and law to standardize the industry development if we really want to develop our modern logistics industry.

\subsection{Strengthen the association's self-discipline and mediatory function}

LAC and CFLP have begun to perform the industry function to mediatory and self-discipline. They started to statistic the basic industry index, but energy consumed and emission reduction data did not enter into the category. They are not within the statistic system which include the data of energy consumed, the efficiency of energy using, the condition of energy saving and emission reduction. So, we suggest that LAC and CFLP 
should charge for the work, which means they should impel logistics "energy saving and emission reduction," try their best to do well the statistic of "energy saving and emission reduction" work, before the government construct the uniform organization.

In order to exert the logistics association's function in Supervision and Management, we should strengthen and clear its function and power. The government should give more support to the association while the association should self-consciously perform its function to link between the preceding and the following which means connection, communication, supervision, restriction, and should assist the government to make and implement the logistics industry development program and criterion system etc. The association should actively impel our logistics corporation to modern system with good credit, criterion and high technology. At the same time, it also should do well the work that including drumbeating, supervision, management and statistic.

\subsection{Set up modern logistics structure, distribute resource reasonably}

We should gradually set up modern logistics industry structure which can make resource distribute reasonably, the whole industry level improve, "energy saving and GHG reduction." Logistics infrastructure constitutes with different transits, cross centers and goods sort terminal. It is the basic that include how to layout reasonably and link efficiency the railway, road, water carriage, air-ferry and storage department. It also is key crux about how to improve logistics efficiency and how to save energy and reduce emission. The relating departments should more consider about how to arrange reasonably carries capability, set up logistics establishment, exert its result force, avoid existing resource leaving unused. Logistics basic equipment manufacturing industry also is key crux for improving the whole equipment system and "energy saving and reduction emission." The idea of saving energy and reducing emission should impenetrate the entire process including design, product and using the basic equipments that include container, freight car, railroad van, cargo ship, freight aircraft, storage equipment, load and unload tool, transportation equipment, tally and sort equipment, logistics tool etc. we should precedence consider the demand for "energy saving and emission reduction" in technology.

\subsection{Develop special logistics, reduce energy wasting meaningless}

Specialization is the general trend for logistics what means social division and modern. Specialization logistics already is the main body of logistics industry in developed country while many corporation logistics organized mainly by itself in our country. Material's logistics are finished by third party only is $18 \%$, commodity selling is $16 \%$ in Chinese corporation. What make our logistics industry running efficiency very low, waste severity in 
energy consumed and the effect of "saving energy and reduction emission" is not obvious. We suggest that we should positively develop modern specialization logistics through applying information technology; positively shape specialization logistics servicing corporation with information, intelligent, integrated and individual service. We can increase the logistics efficiency and reduce energy consumed and emission through developing specialization and scalization.

\subsection{Promote logistics industry develop, energy saving and emission reduction through accelerate constructing logistics information system}

The information network is a lifeline for modern logistics. It can come to true that logistics service supplier can share resource with client, manufacturer, supplier; can tract their material flowing at every process in real time; achieve to availability control and entirely manage. Logistics service supplier may realize most efficiency distribution, cut down empty running ratio and meaningless energy consumed, consequently, decrease logistics running cost and increase corporation benefit.

The government should organize cogent scientific research groups to tackle the key problems of logistics information; realize its commodity, database, code, deal electron and computer; strengthen logistics information transmission standard, real time; information storage series, standardization, form manipulate process and manage text. The Association should propel the information system to applying, frame logistics service standard and criterion by learning international mature logistics technology and service criterion. The logistics corporation should quickly spread and apply the information technology. We can increase our logistics efficiency, reduce meaningless empty running and equipment leaving unused ratio, realize resource distribution optimization, achieve the target to "energy saving and emission reduction," through logistics information and net technology research, spreading and applying.

\subsection{Constitute development policy to support and strength the degree to 'Energy saving and emission reduction'}

"The eleventh five" program has clearly put forward the tasks that are "promote modern logistics management technology, foster special logistics corporation, constitute logistics standard system and strength infrastructure conformity." In "About some opinion of accelerating service industry by state department" pointed that we should upgrade the level of logistics specialization, socialization and actively develop the third party logistics. It is reported that "the nation scheme of develop program for modern logistics" will be about 
constituted and published.

The government should constitute a homologous policy about tax, traffic, financing which are all hotspot or difficult questions based on the spirit of "The eleventh five" program and some relating document by state department and the develop program of logistics industry, to give more support develop policy; to lead, drive the logistics optimize and upgrade; to accelerate establish modern logistics service system. So, we can gradually establish our sustainable development system of modern logistics and high efficiency, saving energy and reduction emission. Additionally, the logistics development policy should strengthen favorable tax to "energy saving and emission reduction"; The policy should inspire and support to technology researching and applying. So, we can create a good condition for our logistics sustainable development and the task to save energy and reduce emission.

\subsection{Strengthen the consciousness of logistics enterprise's "Energy saving and emission reduction"}

The tasks to "energy saving and emission reduction" finally carry out by each corporation, the ultimately effect rest on the cognition and endeavor by individual corporation. The effect of logistic corporation is comparatively laggard to other high energy consuming industries. The main reason is that the cognition of global warming's severity is not enough for our logistics corporations and its contribution to Global Warming can't understand by our logistics corporations. Even more, the corporations can't understand the signification of "energy saving and emission reduction" for them to reduce cost, improve efficiency and capability for profit. We should cultivate and strengthen the consciousness to save energy and reduce emission for our logistics corporation at their developing and operating process because they lack the consciousness and effort.

The consciousness to "energy saving and emission reduction" requires many processes and various efforts. First, the logistics association or relating industrial organizations should understand the severity of Global Warming and the general trending, significance and pressure to "energy saving and emission reduction" for industry; secondly, the industry organization should propagandize and implement the task of "energy saving and emission reduction," strengthen the concept and consciousness to the corporate leader; thirdly, the corporate leader should propagandize and implement the task of "energy saving and emission reduction," strengthen the task to every job and every employee. Lastly, every employee in the logistics industry should have the conception to save energy and reduce emission and carry out it in daily work. Only in this way, we can achieve the task of "energy saving and emission reduction" and the sustainable development at most degree. 


\section{References}

Hu, Angang. 2008. The road map of global emission reduction to Copenhagen. Dang Dai Ya Tai. No.6. pp. 22 38.

Intergovernmental Panel on Climate Change (IPCC). 2007. Climate Change 2007: Summary for Policymakers. UK: Cambridge University Press.

Jiang, Zengwei. 2008. Develop Modern Logistics and Promote the Modernization of Marketing and Distribution. China Circulation Economy. No.2. pp. 4-7

Jun, Pang. 2008. A Review on the Research of Energy Conservation and Emission Reduction Policies. Ecological Environment. No.9. pp. 136-138.

Li, Ling Shao and Qiujun, Gu Wei. 2008. Advanced Experience on the Abroad Logistics Industry Development. Logistics Management, No.10. pp 20-21.

Liu, Yong-hong and Li, Hui-jun. 2008. Using the Information Technology to Accelerate the Development of Our Modern Logistics. Logistics Sci-Tech No.1. pp 129-131.

Lu, Jiang. 2008. The situation analysis and prospect of China logistics development. Hong Guan Jing Ji Guan Li. No.3. pp 16-21.

McKibbin, W.J and Wilcoxen, P.J. 2002. The role of economics in climate change policy. Journal of Economic Perspective. No.16. pp. 107-129.

Wu, Qiaosheng and Cheng, Jinhua. 2003. Policies study on global climate change. China Soft Science, No.9. pp. 14-20.

Wu, Yujie. 2008. The Status of the Logistics Industry and the Building of Legal Environment System in China. Logistics Management. No.3. pp. 14-15.

Zhuang, Guiyang. 2008. Post Kyoto International Climate Governance and China’s Strategic Options. World economic and policy. No.8. pp 6-15.

- Websites

http://www.ipcc.ch/

http://www.ipcc.cma.gov.cn/cn/

http://www.stats.gov.cn/

http://csl.chinawuliu.com.cn/

http://www.chinawuliu.com.cn/

http://www.most.gov.cn/

http://csl.chinawuliu.com.cn/ 
